Document downloaded from:

http://hdl.handle.net/10251/103767

This paper must be cited as:

C. Guardiola; J. Martín; B. Pla; Bares-Moreno, P. (2017). Cycle by cycle NOx model for diesel engine control. Applied Thermal Engineering. 110:1011-1020.

doi:10.1016/j.applthermaleng.2016.08.170

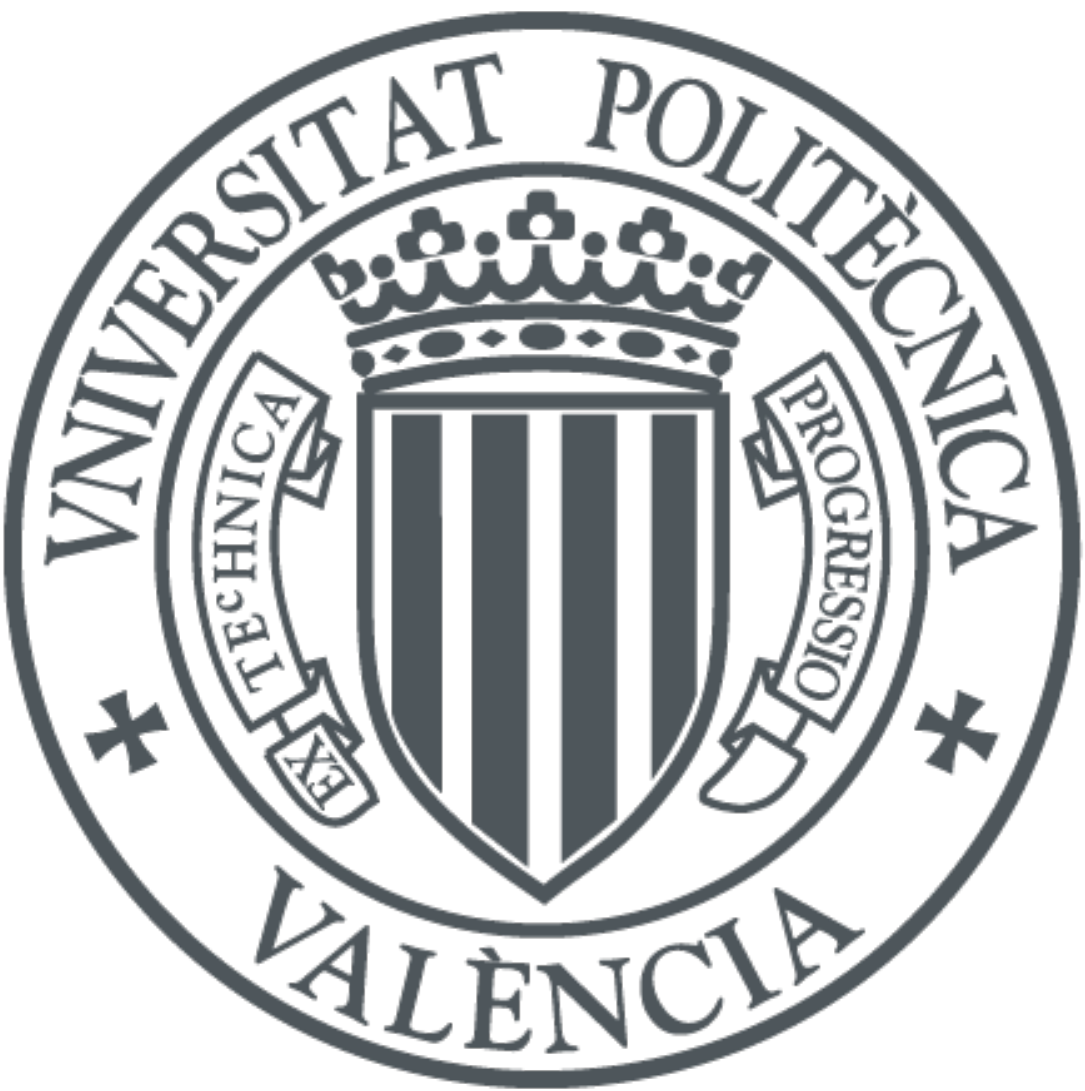

The final publication is available at

http://dx.doi.org/10.1016/j.applthermaleng.2016.08.170

Copyright Elsevier

Additional Information 


\title{
Cycle by cycle NOx model for Diesel engine control
}

\author{
C. Guardiola, J. MartTín, B. Pla and P. Bares* \\ CMT-Motores Térmicos, Universitat Politècnica de València
}

\begin{abstract}
This paper presents a model for on-line NOx estimation. The method uses both, low frequency components and high frequency components of in-cylinder pressure signal: it harnesses in-cylinder pressure resonance to estimate the trapped mass, and based on this measurement, a NOx model is adapted to estimate NOx emissions cycle by cycle.

In addition of the in-cylinder pressure signal, the procedure only requires from lambda and air mass flow to estimate NOx, so it can give a direct estimation of NOx or improve transient response and ageing of current NOx sensors. The method was validated on a CI engine with high pressure EGR loop under steady and transient conditions showing errors below $10 \%$ and cycle by cycle time response.
\end{abstract}

\section{AbBREVIATIONS}

BMEP Break Mean Effective Pressure

CAD Crank Angle Degree

CI Compression Ignited

ECU Electronic Control Unit

EGR Exhaust Gases Recirculated

HCCI Homogeneous Charge Compression Ignited

HRL Heat Release Law

HRR Heat Released Rate

LNT Lean NOx Trap

LTC Low Temperature Combustion

MAE Mean Absolute Error

MAF Mass Air Flow

MRE Mean Relative Error

NO Nitrogen Oxides

OP Operating Point

PEMS Portable Emission Measurement System

SOI Start Of Injection

SCR Selective Catalytic Reduction

TDC Top Dead Center

\section{INTRODUCTION}

$\mathrm{N}$

EW stringent antipollution diesel legislation is forcing Diesel engines to reduce NOx production. Furthermore future European emission legislation will probably include Portable Emissions Measurement Systems (PEMS) to control pollutant emissions onboard [1, 2] paying more attention to real transient engine behaviour, which is one of the main cause of pollutants [3].

Lots of authors have published works about posttreatment systems, such as Lean NOx Trap (LNT) or
Selective Catalytic Reduction (SCR), to overcome that issue [4]. Post-treatment systems allow lowering pollutants to standard legislation but have important fuel penalties associated. Some authors are studying new combustion strategies, such us water injection [5] or eliminating NOx-soot trade-off by using new combustion modes [6]. These strategies promise reducing NOx pollutants, but robustly controlling an efficient combustion is still in research. Finally some others suggest closed loop NOx control, if a fast and reliable NOx measurement is available [7, 8$]$.

Regardless of the final strategy, improving transient operation requires from fast and accurate onboard NOx measurement. Although NOx sensors are currently being installed on commercial engines [9], they do not have an optimal time response for transient operation (around $750 \mathrm{~ms}$ [10, 11]). NOx models present an opportunity to improve transient sensor response by online model adaptation [12], or even to replace physical sensors and lowering then the costs.

Ranging from physics-based models, which rely on complex thermodynamics and combustion processes, to black box models, which have no representation of physics phenomena, NOx modelling has been a trade-off between physics fidelity, calibration effort and computational cost [13, 14, 15].

NOx models are usually based on thermal NOx formation, strongly dependent on the high temperatures of the flame [16, 17]. These models are aimed to calculate NOx production through the approximation of the temperature of the reaction, which drives the NOx formation rate. Some of them do not need

${ }^{*}$ Correspondent author: pabamo@mot.upv.es 
in-cylinder pressure signal and use semi-empirical models relying on available signals on current Electronic Control Units (ECU), such as intake pressure or temperature, and try to approximate a representative temperature for all the cycle [18, 19]. Others, using incylinder pressure information, try to approximate the reaction temperature during combustion [20, 21, 22] and obtain the final NOx production by integrating the instantaneous NOx formation.

Regarding in-cylinder pressure sensors availability in commercial engines, because of combustion control demmands and because of the lowering cost of new incylinder pressure sensors, many companies are thinking about its nearby implementation. Indeed, methods using in-cylinder pressure sensors are of high interest [23], and many methods are being developed for determining combustion features, e.g. combustion detection [24, 25], combustion control parameters [26], noise evaluation [27], air mass estimation [28], heat transfer [29, 30, 31] ...

Although thermal mechanism does represent most of NOx produced by diffusive flame combustion, two important effects occur at the same time. On one hand some of the NOx produced are re-entrained into the diffusive flame and most of them are destroyed when passing through the flame. The reduction mechanism was proved by artificial NO insertion by F.Payri et al. in [32] and a reduction correction was proposed by J.Arregle et al. in [33]. On the other hand, other formation mechanisms can represent an important percentage of the total NOx when temperatures are low [34]. These mechanisms take importance when new combustion strategies are applied, such as Low Temperature Combustion (LTC).

Unfortunately NOx modelling is extremely sensitive to in-cylinder temperature estimation and hence trapped mass assumptions. According to J. Arrelge et al. a 5\% error in the trapped mass leads to a $98 \%$ error in the predicted NOx [33]. Air mass flow is measured by hot film anemometer and is commonly available on commercial ECUs, howeverm they can suffer from important bias, up to $5 \%$. The main handicap when inferring the trapped mass and its composition is related with EGR estimation [35], which is not measured in most of commercial applications. There are different approaches to calculate the trapped mass:

- Volumetric efficiency: Some on-board applications estimate the trapped mass by volumetric efficiency assumption [36], which is specially not advisable for transient operation, not only because of the volumetric efficiency map interpolation, but also because of the slow time response of thermistors at intake (around $2 \mathrm{sec}$ )[37].

- Summation of terms: In research test benches, EGR can be measured by $\mathrm{CO}_{2}$ balance through intake and exhaust manifold concentration measuring. This is the most extended methodology for research and for performing a fine efficiency map calibration. However, EGR distribution over cylinders and an incorrect position of the pollutant analyser prove can easily derive into huge errors [38]. In on-board applications, EGR mass flow, as well as residuals or shortcircuit can be modelled by valve models [39, 40] but at the expense of relying on the conditions around the valve, which are difficult to measure with precision and need from slow sensors such as thermistors.

- Alternative methods: By relaying on different phenomena, such as politropic compression on the $\Delta p$ method [28, 41]. Such methods are normally restricted to a small range of the operating conditions, mainly due to the sensitivity of these methods to disturbances.

The present paper studies NOx formation in order to improve current models precision by taking profit of in-cylinder pressure resonant modes. It proposes a method capable of determining NOx emissions with one cycle resolution, by relying only on the pressure signal, the air mass flow and lambda.

The new NOx model presents two important contributions: First, although it was adapted from previous works of the authors [20], a different parametrization is proposed. Doing so, thermal mechanism can be separated from other NOx formation mechanisms. And secondly, errors at trapped mass estimation when using traditional methods are evidenced. The high sensitivity of NOx models to MAF and EGR errors has turned away its implementation on current applications, however, by using resonant modes, as proposed by the present work, its applicability to research test benches, but also on-board in commercial engines seems realizable.

The paper is structured as follows: section 2 describes the engine and the facilities for obtaining the data. Section 3 is aimed to present the method. Section 4 shows a comparative between the method and NOx sensors on real data and section 5 concludes with 
the strengths of the method and its limitations.

\section{EXPERIMENTAL SETUP}

Experimental tests were carried out in a four-stroke diesel engine with 1.5-1 of total displacement. It is a four-cylinder engine with a turbo-charger and equipped with common rail injection system. Table 1 summarizes the main engine characteristics.

Table 1: Main engine characteristics

\begin{tabular}{lcc} 
& Units & Value \\
\hline Stroke & {$[-]$} & 4 \\
Combustion type & {$[-]$} & $\mathrm{CI}$ \\
Unitary displacement & {$[\mathrm{cc}]$} & 374.65 \\
Bore & {$[\mathrm{mm}]$} & 73.5 \\
Compression ratio & {$[-]$} & $17: 1$
\end{tabular}

Aside from measures coming from ECU and test cell sensors, a special effort was done to analyse online NOx and pressure signal in a synchronous way in order to determine the physical phenomenon taking place in the engine for modelling NOx engine-out emissions.
All measurements coming from ECU, test cell and additional sensors employed were recorded by different acquisition systems to deal with different communication protocols and different acquisition rates. Four acquisition systems were employed:

1. A PUMA acquisition system was used to collect all test cell sensor and extra thermocouples data with an acquisition rate of $10 \mathrm{~Hz}$.

2. An ETAS system was programmed to connect with the ECU and download a selected set of variables from the ECU at $100 \mathrm{~Hz}$. A computer was connected with Ethernet protocol to process and save the data.

3. An Horiba system was connected by serial port to another computer, the data was recorded at $10 \mathrm{~Hz}$.

4. A PXI-RT system was employed for acquiring and processing the data from the smart NOx sensor and all other data needed for the final diagnosis algorithm which require from high acquisition rates. In-cylinder pressure was obtained by a AVL GU13P acquired at $0.2 \mathrm{CAD} /$ sample, while CAN protocol was programmed to interact with the smart NOx sensor.

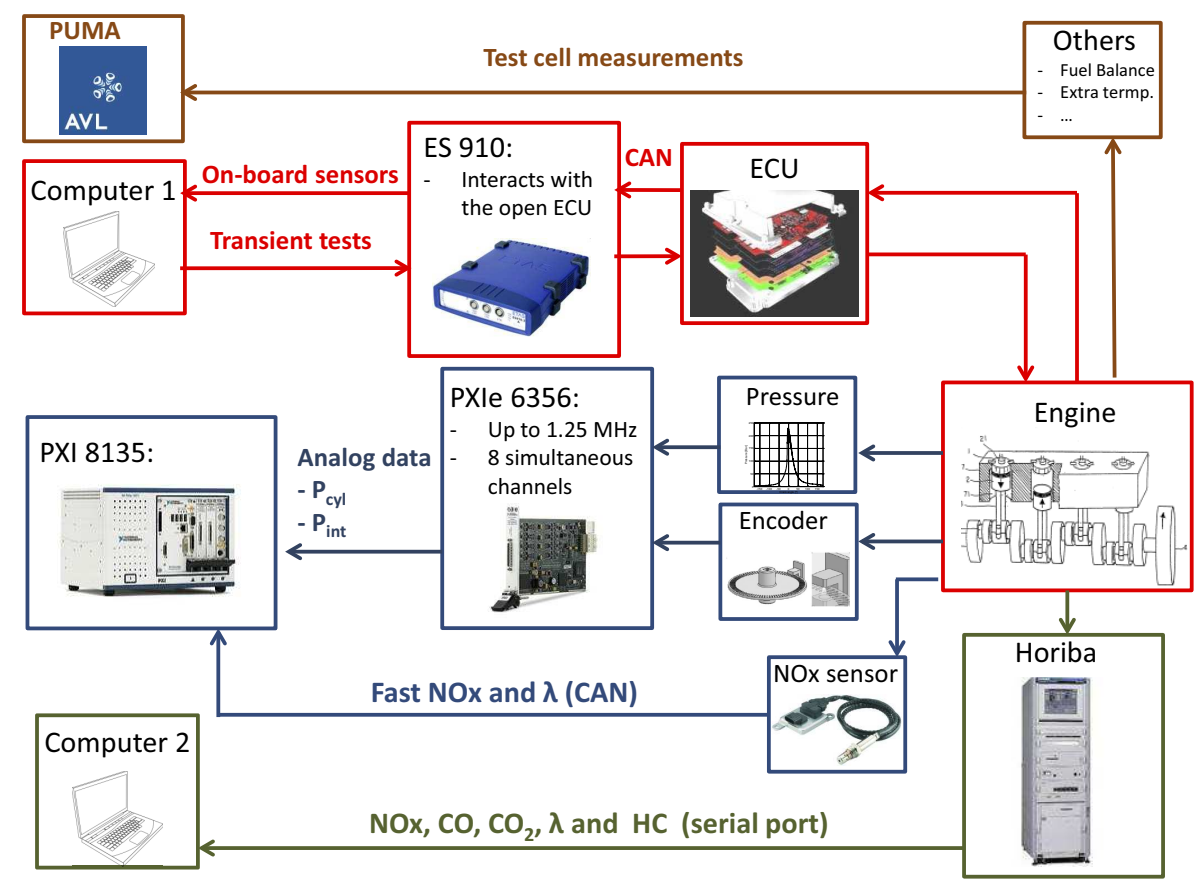

Figure 1: Data acquisition layout 
All systems were synchronized by a clock signal sent from PXI to all other acquisition systems. Figure 1 summarizes the acquisition process.

Exhaust gas concentration was determined by using an exhaust gas analyzer Horiba MEXA7100D for steady operation and a Continental Smart NOx sensor for transient tests. Both systems give also a lambda measurement for comparing with the onboard lambda sensor. Figure 2 shows a comparison between the NOx obtained by the Smart NOx sensor and the NOx obtained by the Horiba system over 39 operation points ranging from 0 to $100 \%$ load and from $1000 \mathrm{rpm}$ to $3000 \mathrm{rpm}$ of engine speed. Horiba was corrected by humidity following European lightduty vehicles emissions normative [42].

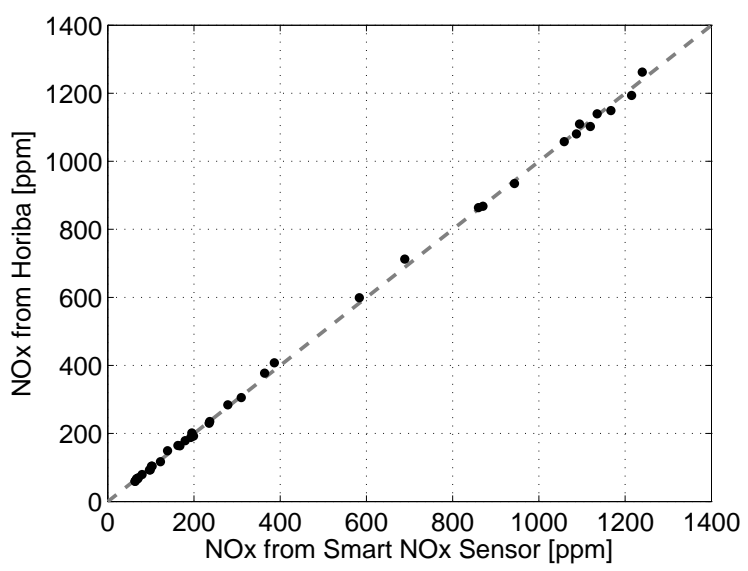

Figure 2: Comparation between Horiba system and smart NOx sensor

\section{Method DESCRIPTION}

In-cylinder pressure signal provides many information about combustion evolution. However, all phe- nomena taking place simultaneously appear on the pressure signal. Three important phenomena can be distinguished: pseudo-motored, combustion and resonance. Each of them does appear at different zones in the frequency band: the movement of the piston is related with frequencies below $500 \mathrm{~Hz}$, combustion and the pressure variations caused are normally located between $500 \mathrm{~Hz}$ and $2 \mathrm{kHz}$, finally, the acoustical waves produced by combustion, resonate at punctual frequencies, which are function of the resonant modes and the engine size [43].

Combustion models have traditionally used low frequency components of the pressure signal (pseudomotored and combustion) to determine the combustion evolution and they laid aside high frequency components as noise. In the present method pressure signal is divided in the frequency range: resonance at the high frequency band is used for inferring the trapped mass, while low-frequency components are used to estimate the adiabatic flame temperature $\left(T_{a d}\right)$ and the heat released rate (HRR).

The rate of heat released and the adiabatic temperature are used to estimate NOx raw production by the thermal mechanism. This NOx estimation must be corrected to take into account NOx reduction, caused by re-entrant NOx into the flame and existing NOx in EGR. Finally, thermal NOx are corrected for other formation mechanism when oxygen concentration is low (LTC combustion).

Figure 3 shows an schema of the full method for NOx estimation. It must be noticed that the full system only requires from in-cylinder pressure, lambda and air mass sensors. 


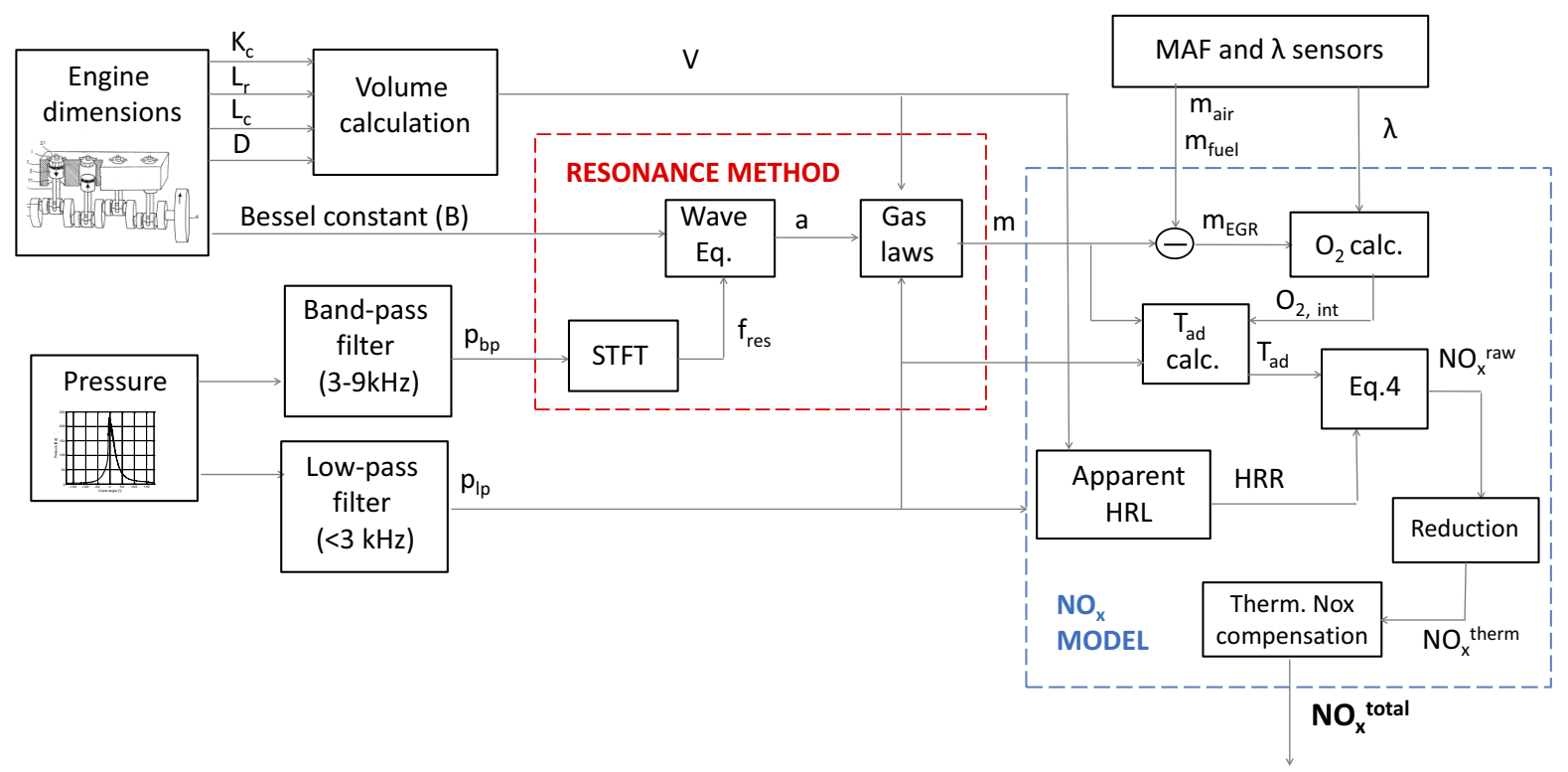

Figure 3: Complete Scheme of the method proposed

\section{Trapped mass estimation}

Resonance is normally considered as an undesired phenomena responsible of noise in diesel engines [27] and a limiting factor in Spark Ignited Engines [44]. However, past works of the authors estimated the trapped mass by relying on the resonant frequency of the first radial mode.

Trapped mass determination is based on profiting the existence of resonant modes in the in-cylinder pressure, which are excited as a consequence of the combustion. As known from [45], resonant frequency depends on cylinder geometry and the speed of sound, following:

$$
f_{\text {res }}(\alpha)=\frac{a(\alpha) B}{\pi D}
$$

where $a$ is the speed of sound, $f_{\text {res }}$ is the resonant frequency, $B$ is the Bessel coefficient for the first resonant radial mode, $D$ is the cylinder bore and $\alpha$ represents the crank angle evolution.

$R$. Hickling et al. were the first authors trying to take advantage of resonance by measuring the oscillation period and estimating the bulk temperature [46]. The approach was finally systematized by C.Guardiola et al. for obtaining the trapped mass by using ShortTime Fourier Transform(STFT) for inferring the resonant frequency and assuming ideal gas via Eq. 2 for finally determining the trapped mass [47, 48].

$$
m(\alpha)=\frac{\gamma(\alpha) p(\alpha) V(\alpha)}{a(\alpha)^{2}}
$$

where $p$ is the in-cylinder pressure, $V$ the instantaneous cylinder volume and $\gamma$ is the ratio between constant pressure and constant volume heat capacities $\left(c_{p} / c_{v}\right)$.

Although processing the pressure signal by timefrequency analysis its too computationally demanding for conventional ECUs, a specific transformation was published by the authors in [49]. This transformation avoids time-frequency calculations and does intrinsically eliminate faulty measurements, because the amplitude of the peak is directly related with a coherent resonant frequency evolution.

\section{Thermal NOx formation}

Most of NOx on CI combustion are due to thermal formation. Thermal formation is representative when temperatures are high and the relative air to fuel ratio is close to 1 , as in the flame front in CI combustion. The reactions that take part on this mechanism were described firstly by Zeldovich [50] and later extended in what is named extended or modified-Zeldovich mechanism [17], described by the following reactions:

$$
\begin{aligned}
\mathrm{N}_{2}+\mathrm{O} & \leftrightarrow \mathrm{NO}+\mathrm{N} \\
\mathrm{N}+\mathrm{O}_{2} & \leftrightarrow \mathrm{NO}+\mathrm{O} \\
\mathrm{N}+\mathrm{OH} & \leftrightarrow \mathrm{NO}+\mathrm{H}
\end{aligned}
$$


However a detailed model taking into account all chemical kinetics would be unfeasible for practical applications and most of NOx models are based on a single global reaction. The instantaneous production of this reaction is dependent of the reactants concentration and a reaction rate. The reaction rate is modelled with an Arrhenius-like function, such as:

$$
r_{\text {reac }}=e^{-k_{\text {act }} / T_{\text {reac }}}
$$

This reaction takes place at high temperatures, when oxygen is available. Even thought in CI engines the highest temperatures are produced at the diffusion flame front, NOx can not be produced because of oxygen lack. The boundary layer where NOx are created is located between the diffusive flame and a small distance, where temperature falls down but more oxygen is available. The thickness of this layer depends on the operating point, e.g. if the flame is turbulent or laminar. The temperature governing the chemical kinetics is assumed to be close to the adiabatic flame temperature but differing a $\Delta T$, which depends on the combustion flame and thus the operating point considered:

$$
T_{\text {reac }}=T a d+\Delta T(n, N)
$$

The reactant concentration is mainly function of the mass flow through the flame and therefore can be considered proportional to the mass fuel burnt and hence the heat release rate (HRR). Leading to a simplified thermal NOx model such as:

$$
d N O x^{\text {th }}(\alpha)=k_{f} H R R(\alpha) e^{-k_{\text {act }} / T_{\text {reac }}(\alpha)}
$$

where $k_{f}$ represents the proportionality between $H R R(\alpha)$ and the amount of reactants passing through the flame.

Finally, integrating over combustion, it yields:

$$
N O x^{\text {th }}=\int_{S O C}^{E O C} k_{f} H R R e^{-\frac{k_{a c t}}{\operatorname{Tad}+\Delta T(n, N)}} d \alpha
$$

where $\operatorname{HRR}(\alpha)$ and $T_{a d}(\alpha)$ can be obtained from pressure signal.

$\operatorname{HRR}(\alpha)$ is normally calculated by substituting in the first law of thermodynamics $(\mathrm{dU}=\mathrm{dQ}+\mathrm{dW})$ the expressions of $\mathrm{dU}$ and $\mathrm{dW}$, which yields:

$$
d Q=H R R-d Q_{w}=\frac{\gamma}{\gamma-1} p d V+\frac{1}{\gamma-1} V d p
$$

where $d Q$ represent the net heat release, $d Q_{w}$ is the heat losses through the walls.
Herein, different alternatives are used depending on the requirements of the application. For being absolutely consistent, $\gamma$ should be estimated through the composition and temperature of the chamber, such as [51] propose, and semi-empirical equations should model wall heat transfer in order to obtain the chemical energy released or gross heat released [31] (e.g. Whoschni correlation [52]). But in many applications, there are many simplifications for avoiding such calculations, which have tedious and complicate calibration procedures: simplified gross heat release calculation can be obtained by considering $d Q_{w}$ throughout using a polytropic exponent $k$ instead of $\gamma \cdot 1.3$ was found to be representative of combustion in many works but can be also computed on-board during compression and expansion [53, 54]. In this works, the second option was selected looking at the future applicability in commercial ECUs.

Regarding adiabatic flame temperature estimation, [20] propose a formulation that accounts for the shift in temperature due to the heat released during combustion $\left(\Delta T_{n d}\right)$ and a correction that accounts for the energy absorbed by the partial dissociation of the combustion products $\left(\Delta T_{\text {diss }}\right)$.

$$
T_{a d}=T_{u b}+\Delta T_{n d}-\Delta T_{\text {diss }}
$$

where $T_{u b}$ is the unburned gas temperature calculated from the in-cylinder pressure sensor by

$$
T_{u b}^{n}=T_{u b}^{n-1}\left(\frac{p^{n}}{p^{n-1}}\right)^{\frac{\gamma-1}{\gamma}}
$$

which relies on the trapped mass $(m)$ to obtain the temperature and on the chamber conditions before combustion starts.

$$
T_{u b}^{1}=T^{S O C}=\frac{p^{S O C} V^{S O C}}{m R}
$$

The temperature increase due to heat released is only function of the oxygen, following:

$$
\Delta T_{n d}=37630.5\left(\frac{Y_{\mathrm{O}_{2}}}{3.48}\right)
$$

The oxygen introduced in the chamber $\left(Y_{\mathrm{O}_{2}}\right)$ is computed from lambda, by neglecting cycle by cycle variations on EGR composition.

$$
Y_{\mathrm{O}_{2}}=\frac{m_{E G R}\left(Y_{\mathrm{O}_{2}}^{a t m} \frac{1-1 / \lambda}{1+F_{s t} / \lambda}\right)+m_{\text {air }} Y_{\mathrm{O}_{2}}^{\text {atm }}}{m_{E G R}+m_{\text {air }}}
$$


where $Y_{\mathrm{O}_{2}}^{a t m}$ is set to $21 \%$ and $F_{s t}$ is the stoichiometric ratio between fuel and air $(\approx 0.0676)$.

And finally, the dissociation effects can be described by:

$$
\Delta T_{\text {diss }}=A\left(T_{u b}+\Delta T_{n d}\right)^{B}
$$

In [20] C. Guardiola et al. differenced two zones for being more precise: below $2600 \mathrm{~K}$ where $A=$ $1.55 \times 10^{-7}$ and $B=2.677$ and above $2600 \mathrm{~K}$ where $A=7.136 \times 10^{-10}$ and $B=3.36$.

\section{Reduction mechanism}

The local conditions inside a diesel diffusion flame (a region with high temperatures not far from the adiabatic flame temperature, and a mixture of both, burned and cracked fuel gases) correspond to an even more reducing atmosphere than the one present in the re-burning zone of a thermal power plant, where an important NOx reduction is achieved. Consequently NOx re-entrained into the flame will be almost absolutely destroyed. For simplicity a coefficient $(\epsilon)$ represents the reductant efficiency of the flame.

NOx reduced come from two different sources:

- NOx coming from recirculated EGR: the NOx re-entrained into the combustion chamber from EGR that take part into combustion, if a proper mixing is assumed, are:

$$
N O x_{E G R}^{r e}=m_{E G R} F_{r} Y_{N O x, e x h}
$$

where $m_{E G R}$ are the exhaust gases recirculated, $F_{r}$ is the relative fuel to air ratio and $Y_{N O x, e x h}$ is the NOx mass fraction at the exhaust.

- Re-entrained NOx of the current cycle: some of the products of the diffusive flame can be reentrained into the flame at the same cycle.

At the start of combustion there will be no NOx re-entrained into the flame, but at EOC, if all the products are homogeneously mixed in the chamber, the efficiency will be $F_{r}$. In order to consider all the combustion evolution it is assumed an intermediate situation $F_{r} K_{r e}\left(0<K_{e}<1\right)$.

Figure 4 represents the re-entrant flows and Eq. (14) determines the final NOx concentration at the exhaust:

$$
Y_{N O x, e x h}=\frac{N O x^{\text {th }}\left(1-F_{r} K_{r e} \epsilon\right)}{m_{\text {air }}+m_{f u e l}+m_{E G R} F_{r} \epsilon}
$$

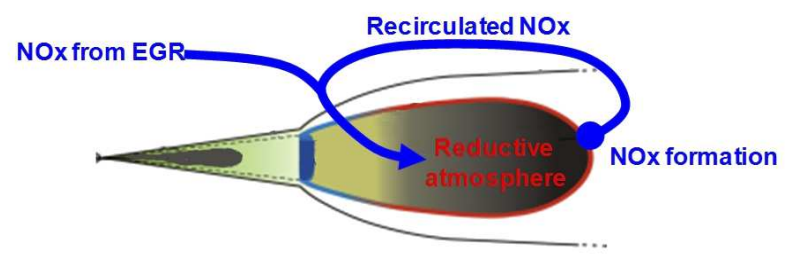

Figure 4: NOx reduction scheme on a diffusive flame combustion

\section{$\mathrm{N}_{2} \mathrm{O}$ and Prompt mechanisms correction}

Although thermal formation mechanism is the most representative of NOx formation on diesel combustion, it is not the only one [55]. Prompt [56] and via $\mathrm{N}_{2} \mathrm{O}$ mechanisms [36] are other important mechanisms of NOx production and they are responsible of an important percentage of NOx under LTC combustion in diesel engines. The relevance of these mechanisms at low temperature was proven by [34] by computing thousands of simulations using worldwide commercial chemical-kinetic software (Chemkin), which can represent more than $50 \%$ of total NOx.

The authors propose modelling the ratio of NOx produced by thermal mechanism and the overall NOx production by a correction factor based on the maximum adiabatic flame temperature, as the adiabatic flame temperature drives the thermal NOx formation. This correction factor ranges from 1 at high flame temperatures, where nearly all NOx are due to thermal mechanism, to almost 0 at low oxygen concentration, where thermal NOx formation is negligible.

A potential function was fitted for cycles with low adiabatic flame temperatures, following:

$$
K\left(T_{a d}^{m a x}\right)=\frac{N O x^{\text {th }}}{N O x^{\text {total }}}=\left(m\left(T_{a d}^{\max }-T_{0}\right)\right)^{n}
$$

\section{Results AND Discussion}

The engine was tested under steady and transient conditions. Steady tests were used to calibrate the method and to analyse its accuracy while transient tests illustrate a resolution of the model of one cycle.

The same methodology was applied using two models: 
- Model A: By assuming all NOx are produced by thermal mechanism and using conventional methods for calculating the trapped mass. This model is similar to the ones currently proposed by other authors, such as [20, 21, 22].

The trapped mass was estimated by modelling the volumetric efficiency with a look up table $\left(\eta_{v}(n, N)\right)$, and later on obtaining the trapped mass through:

$$
m=\frac{\eta_{v}(n, N) V_{d i s} p_{i n t}}{R T_{i n t}}
$$

where intake pressure $\left(p_{\text {int }}\right)$ was measured by a piezoresistive pressure sensor, intake temperature $\left(T_{\text {int }}\right)$ was measured by a thermocouple, the displaced Volume $\left(V_{\text {dis }}\right)$ is a constant parameter of the engine, and the gas constant $(R)$ was assumed 287.

- Model B: Harnessing in-cylinder resonant modes for obtaining the trapped mass and including a correction for other NOx formation mechanism based on the Oxygen availability.

\section{Calibration}

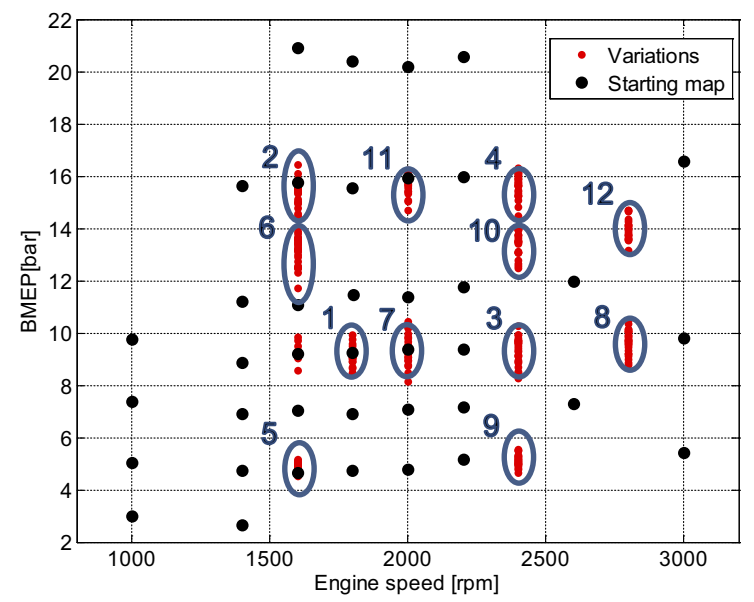

Figure 5: Steady tests performed: Basic operating map shown as black dots, variations over SOI, EGR, intake pressure and rail pressure as small red dots and clusters are marked by circles

Figure 5 shows the operating range covered by the steady tests performed. A starting set of points (with $39 \mathrm{OP}$ ) covering all the operating range was extended by performing variations at the Start of injection (by moving both or only the main injection), intake pressure, Exhaust Gas recirculation and rail pressure. Finally a total of 342 points were measured. At each test, data from 100 cycles was recorded by starting the measurement when operation conditions are stabilized.

The 39 OP from the basic map plus a hundred of test randomly selected were used to train the model while the rest of the tests (203 OP) based on variations of SOI, EGR, rail pressure and intake pressure, guaranteed a fair validation of the data. Note that the operating conditions of the clusters of variations do not necessarily coincide with the basic operating map.

The calibration was divided in three steps: Firstly, tests with no EGR were used to calibrate the volumetric efficiency map, $\eta_{v}(n, N)$, and the Bessel factor, $B(\alpha)$, with an air mass flow sensor. Secondly, tests with high adiabatic flame temperature were selected for characterize the thermal NOx formation mechanism, $\Delta T(n, N)$, by using the smart NOx sensor measurement. And Finally, tests with low flame temperature were employed to fit the correction over the thermal NOx, $K\left(T_{a d}^{\max }\right)$.

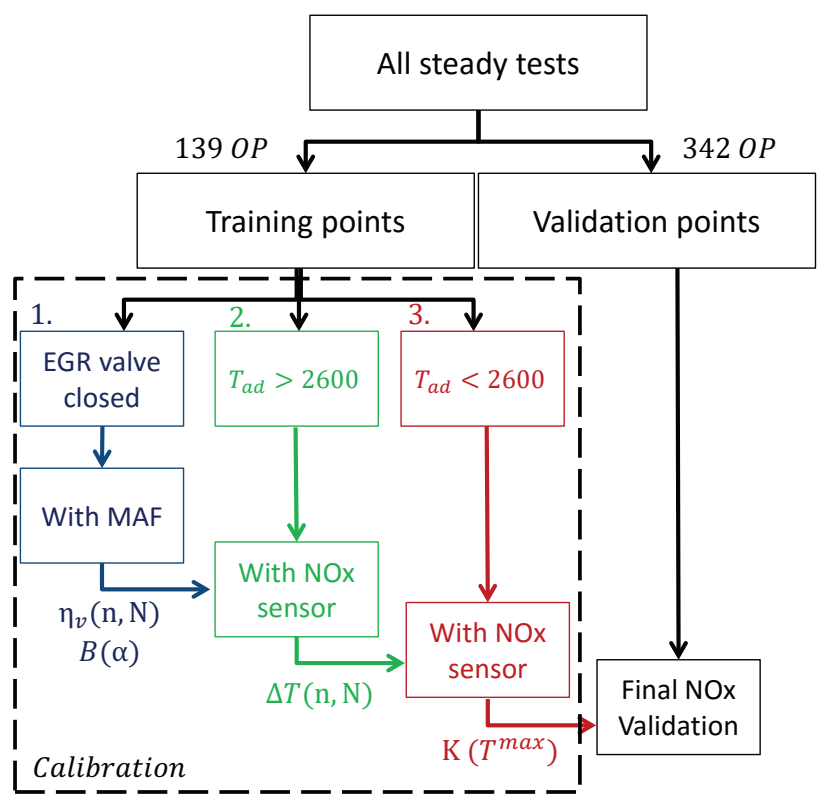

Figure 6: Calibration methodology

Figure 6 illustrates the calibration methodology. Of interest, only variations in maximum adiabatic temperature are mandatory in order to distinguish thermal NOx formation from other mechanism. The easiest way of varying the maximum adiabatic temperature 
is by varying the intake oxygen availability by EGR variations.

- Trapped mass:

Using a test set of OP with EGR valve closed, the trapped mass was estimated by the air mass flow sensor. Figure 7 is the resulting calibration of the volumetric efficiency, ranging from 0.85 to 0.9 in the studied operating conditions.

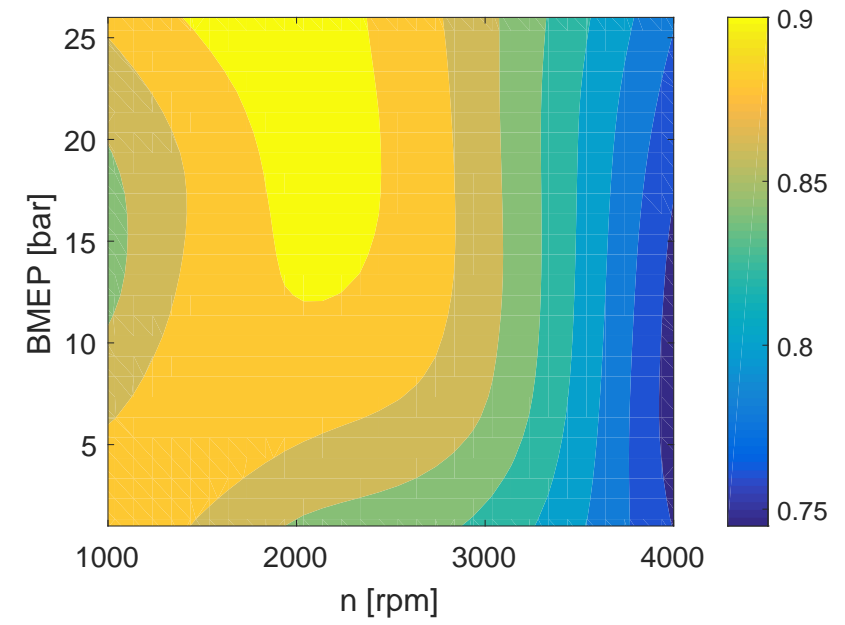

Figure 7: Volumetric efficiency look-up table

The Bessel factor is characterized by geometry and remains invariable when operating conditions change. It can be determined from a detailed study of the geometry by Finite Element Methods or experimentally obtained by timefrequency analysis [57]. In this study, STFT was employed to calibrate it. Finally it was found to be 2.1 at $20 \mathrm{CAD}$ and 1.9 at $50 \mathrm{CAD}$, which are consistent values with the first cylindrical radial mode (1.842).

Figure 8 shows the results of both methods after calibration. It can be noticed that only small discrepancies are found, and both methods provide a valid measurement of the trapped mass when EGR valve is closed.

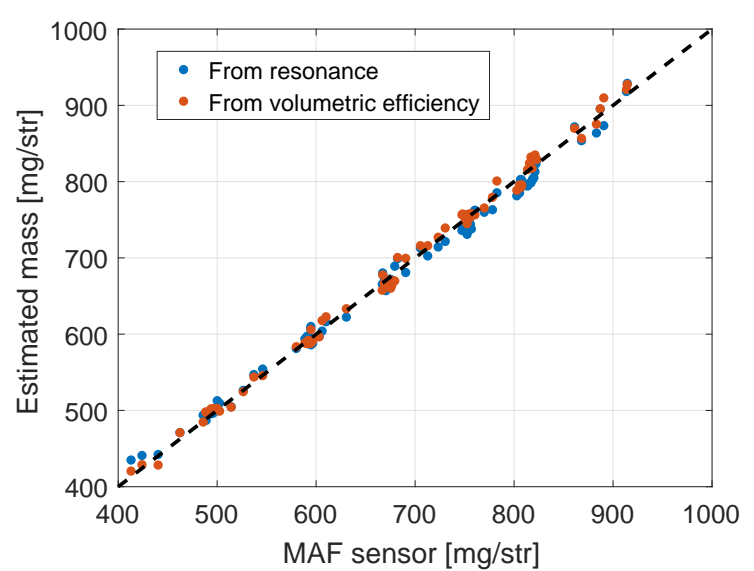

Figure 8: Trapped mass results from calibration

- Reaction temperature correction:

This coefficient is aimed to capture the diffusive flame characteristics by a temperature reaction correction. Diffusive flame combustion was ensured by selecting tests with high adiabatic flame temperatures. Figure 9 shows the final map when using in-cylinder resonant modes for inferring the trapped mass. The correction factor varies from $-60 \mathrm{~K}$ to $-220 \mathrm{~K}$, which is approximately an $8 \%$ of the flame temperature. The boundary NOx production layer length, and hence the temperature reaction reduction seems to increase as load is reduced and engine speed is increased.

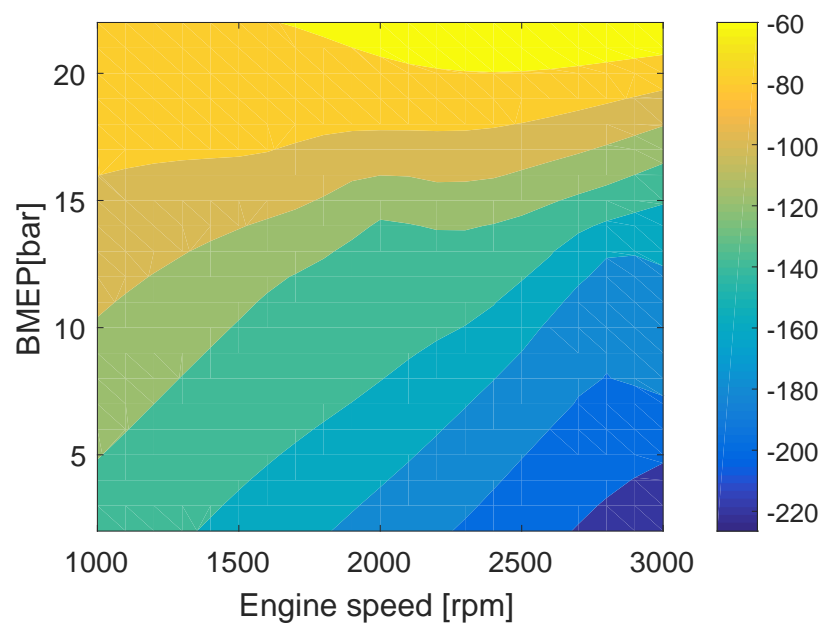

Figure 9: Temperature reaction coorection map obtained from OP of the training dataset with $T_{a d}^{\max }>$ $2600 K$ 
- Prompt and $\mathrm{N}_{2} \mathrm{O}$ correction:

Once the temperature reaction calibration is made, the OP with low adiabatic flame temperatures of the training dataset are used to fit differences between the total NOx measured and the thermal NOx modelled. The identified parameters of equation 15 are 2000, 0.0016 and 2.67 for $T_{0}, m$ and $n$ respectively. Figure 10 shows the ratio $N O x_{t h} / N O x_{t o t}$ measured as a function of the maximum adiabatic flame temperature while using the colorbar for EGR.

It must be noticed that the coefficient strongly depends on the adiabatic flame temperature, the main responsible of LTC combustion. At conventional CI combustion, with no EGR, all NOx are produced from thermal formation. However, at LTC zone $(E G R>30 \%)$ thermal formation explains less than $50 \%$ of the total NOx.

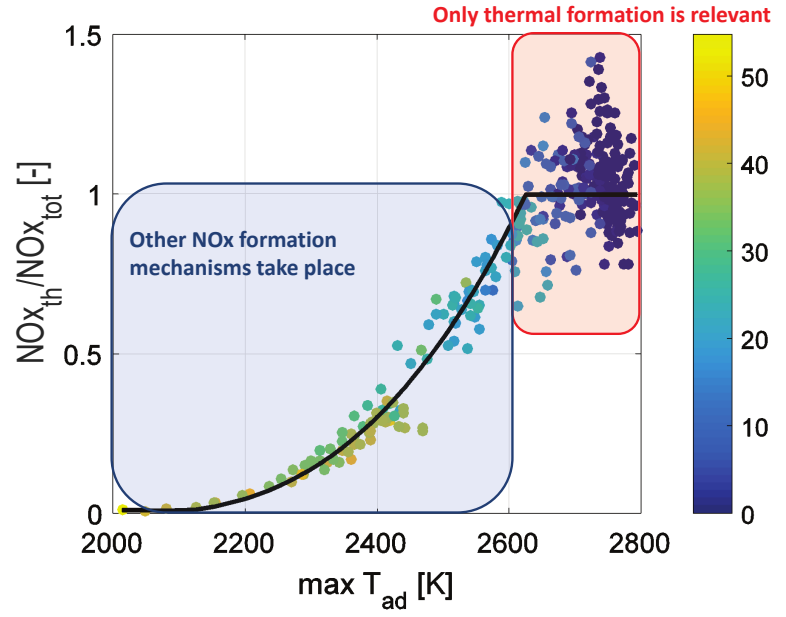

Figure 10: thermal NOx and NOx measured ratio as a function of the maximum adiabatic flame temperature and EGR

\section{Steady results}

As stated, the method was fitted only using the training dataset, which was approximately one third of the tests. Variations made over the clusters shown in figure 5 are tabbed in table 2 EGR, SOI, intake pressure and rail pressure were varied as much as possible, arriving at the limits of misfire and knocking at each configuration.

\begin{tabular}{|c|c|c|c|c|c|c|c|c|c|c|}
\hline \multirow[b]{2}{*}{ Cluster } & \multirow{2}{*}{$\begin{array}{l}\mathrm{n} \text { [rpm] } \\
\text { Average }\end{array}$} & \multirow{2}{*}{$\begin{array}{c}\text { BMEP [bar] } \\
\text { Average }\end{array}$} & \multicolumn{2}{|c|}{ SOI [CAD-TDC] } & \multicolumn{2}{|c|}{ EGR [\%] } & \multicolumn{2}{|c|}{$\mathrm{p}_{\text {intake }}[\mathrm{bar}]$} & \multicolumn{2}{|c|}{$\mathrm{p}_{\text {rail }}[\mathrm{bar}]$} \\
\hline & & & $\min$ & $\max$ & $\min$ & $\max$ & $\min$ & $\max$ & $\min$ & $\max$ \\
\hline 1 & 1800 & 9.13 & -5.01 & 10.00 & & & 1.04 & 1.17 & & \\
\hline 2 & 1600 & 15.23 & -5.01 & 10.00 & 0.00 & 16.84 & 1.16 & 1.91 & 744.25 & 1042.84 \\
\hline 3 & 2400 & 9.23 & -5.01 & 10.00 & 0.00 & 42.85 & 1.14 & 2.03 & 947.20 & 1247.35 \\
\hline 4 & 2400 & 15.60 & -2.50 & 10.00 & 0.00 & 17.53 & 1.37 & 2.40 & 1095.29 & 1394.77 \\
\hline 5 & 1600 & 4.89 & -5.01 & 10.00 & 1.54 & 45.87 & 1.02 & 1.11 & 398.41 & 646.83 \\
\hline 6 & 1600 & 13.18 & -5.01 & 10.00 & 1.06 & 22.96 & 1.15 & 1.90 & 695.65 & 994.72 \\
\hline 7 & 2000 & 9.44 & -2.50 & 10.00 & 1.83 & 32.57 & 1.09 & 1.67 & 698.79 & 998.78 \\
\hline 8 & 2800 & 9.68 & -2.50 & 10.00 & 0.00 & 16.89 & 1.24 & 2.11 & 1097.50 & 1397.42 \\
\hline 9 & 2400 & 5.12 & -2.50 & 10.00 & 1.39 & 47.59 & 1.05 & 1.70 & 647.82 & 947.17 \\
\hline 10 & 2400 & 13.36 & -2.50 & 7.49 & 0.00 & 25.40 & 1.46 & 2.45 & 1046.60 & 1345.62 \\
\hline 11 & 2000 & 15.69 & -2.50 & 7.49 & 0.00 & 19.92 & 1.48 & 2.10 & 893.12 & 1192.90 \\
\hline 12 & 2800 & 13.99 & 0.00 & 10.00 & 0.00 & 18.72 & 1.75 & 2.42 & & \\
\hline
\end{tabular}

Table 2: Seetings variations over clusters shown in figure 5

Figure 11 compares model A and model B with NOx sensor output. Both models were calibrated independently with the same training data set and later compared with the rest of the tests. The $\mathrm{N} 2 \mathrm{O}$ and Prompt correction takes only part when low adiabatic flames and hence at low NOx concentrations. Of interest, model A requires from a thermocouple at the intake, but not model B, and in moreover, model $\mathrm{A}$ has to rely on MAF sensor while model $B$ is able to update MAF bias when EGR valve is closed.

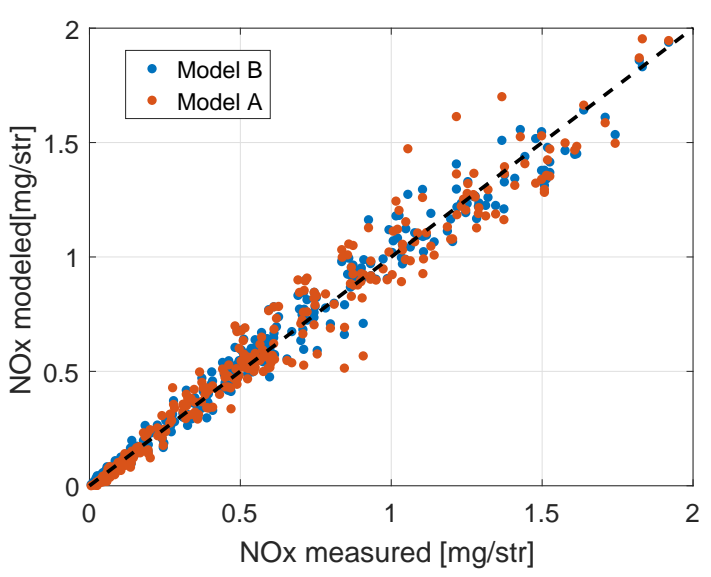

Figure 11: NOx modelled vs. NOx measured 
Errors of figure 11 are summarized in figure 12 by plotting the MAE and the MRE as a function of the total NOx produced.
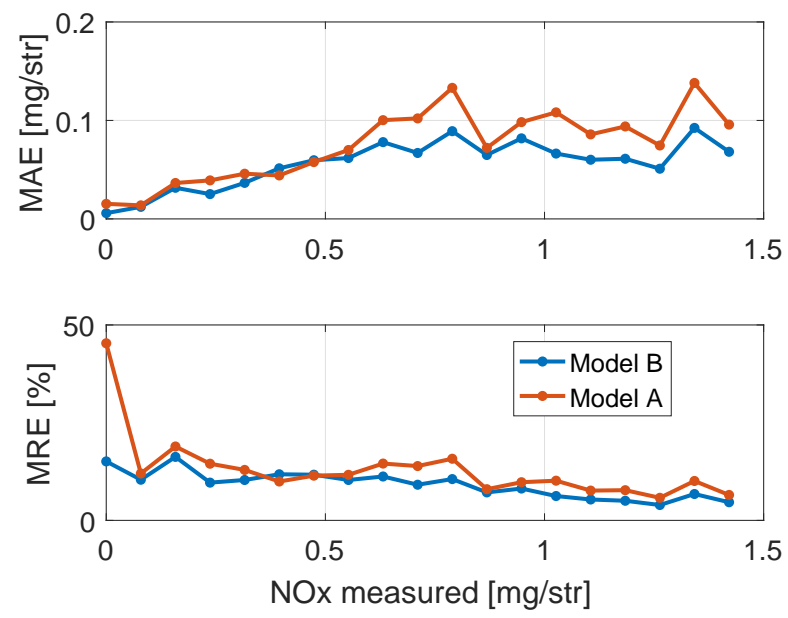

Figure 12: $M A E$ and MRE for model $A$ and model $B$ as a function of NOx

Two important contributions of model B can be derived from figure 12 First, in-cylinder pressure resonance provides an additional measurement of the trapped mass which has lowered the errors of the NOx model a $25 \%$ (from 0.055 to $0.044 \mathrm{mg} / \mathrm{str}$ of MAE). And second, the $\mathrm{N}_{2} \mathrm{O}$ and Prompt correction improves the precision of the model at low NOx concentrations, model $\mathrm{A}$ has almost $50 \%$ error while model B around $15 \%$.

Figure 11 and figure 12 show model results of different operating points doing important variations: SOI was varied from -5 to 10 CAD-TDC, EGR valve command ranged from $0 \%$ to more than $50 \%$, the intake pressure has been modified up to $800 \mathrm{mbar}$ from the base map and the rail pressure up to $25 \%$. Figure 13 splits the model errors in the four inputs variations.

Figure 13 suggests higher model errors when rail pressure or SOI are changed. Rail pressure sensitivity is explained by diffusive flame characteristics, as rail pressure variations do modify the flame length and turbulence. Model errors caused by SOI are meanly due to premixed combustion increase or partial misfires when SOI was set far before from TDC or far after, respectively. It must be noticed that all variations were made at standard engine configuration, so EGR measurement errors can also affect TGV, prail and SOI variations.

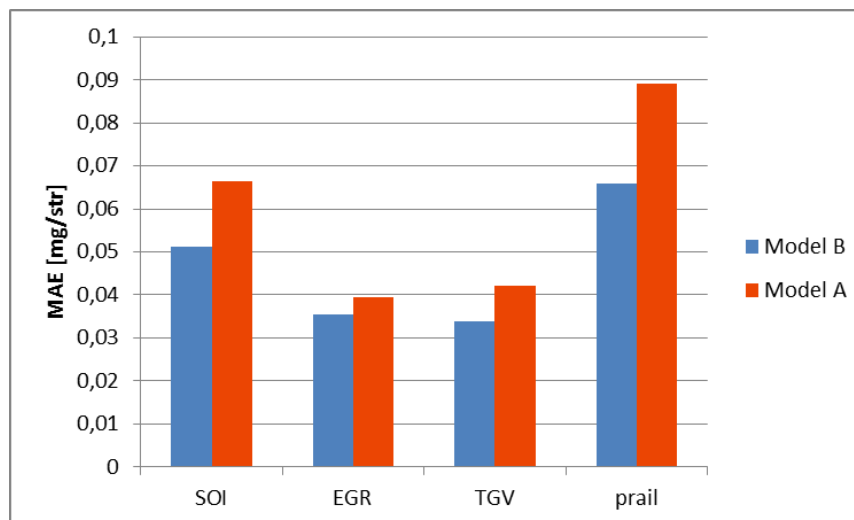

Figure 13: MAE of model $A$ and model $B$ at the different control input variations

\section{Transient tests}

In regard to the time response of the model, steps of different inputs were performed. For a given operating point, EGR valve, SOI, VGT and load have been suddenly changed. When EGR, SOI and VGT steps were performed, the rest of the settings remained constant, but the load steps was performed by varying pedal command so all settings were modified following the standard engine calibration. Models output were filtered with a low-pass filter with an order of 10 cycles. Figures 14[15 and 16 show models output when performing inputs steps at $1600 \mathrm{rpm}$ and $15 \mathrm{bar}$ of BMEP and figure 17 a transient step from 9 to 15.5 bar BMEP at $1600 \mathrm{rpm}$.

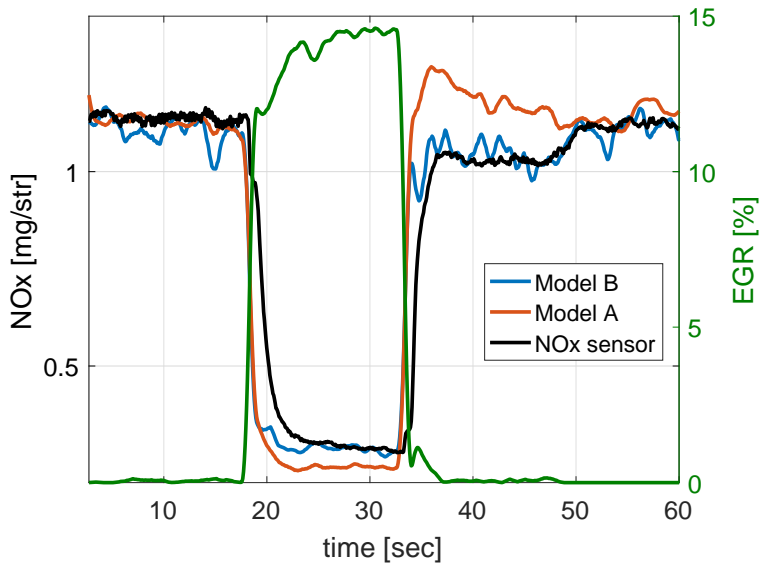

Figure 14: Model A, model B and NOx sensor output when varying EGR at $1600 \mathrm{rpm}, 15$ bar BMEP

EGR step plotted at figure 14implies an important change in NOx production, varying from $1.2 \mathrm{mg} / \mathrm{str}$ when EGR valve was closed to less than 0.2 when $14 \%$ of EGR was applied. The $\mathrm{N}_{2} \mathrm{O}$ and prompt correction 
is responsible of the model $\mathrm{B}$ accuracy between 20 and 32 seconds, when low NOx are measured. From 35 to 50 seconds, the EGR valve is being closed, meanwhile a transient of mass flows and temperatures takes place. During that transient, model B, based on in-cylinder pressure resonance fits better NOx sensor output because of volumetric efficiency interpolation and intake temperature transition which affect model A.

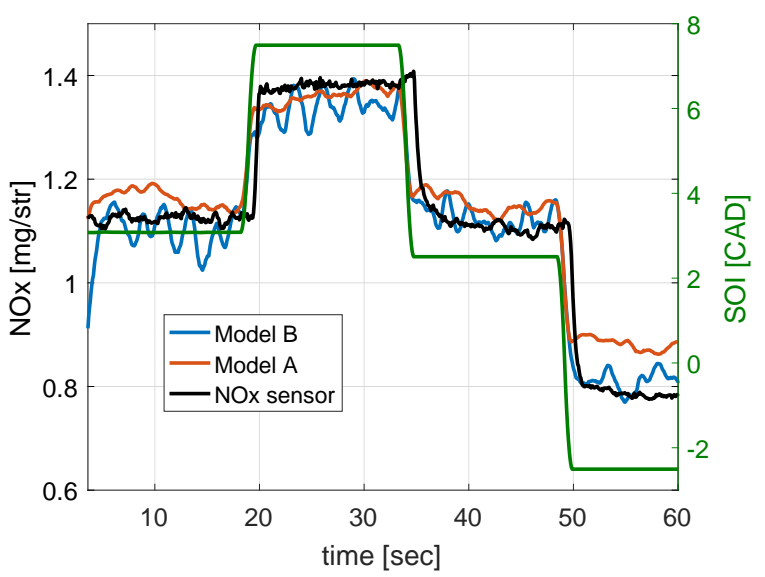

Figure 15: Model A, model B and NOx sensor output when varying SOI at 1600 rpm, 15 bar BMEP

A SOI variation, such as the one plotted in figure 15 should imply an instantaneous change in NOx. Nevertheless, NOx sensor output approximately responds after a second (around 10 revolutions after), it is consistent with some works analysing NOx sensor dynamics, see [58] for more information about NOx sensor time response. This is not the case of NOx models which have an instantaneous variation. This sensor delay can be also detected at EGR, TGV and load steps.

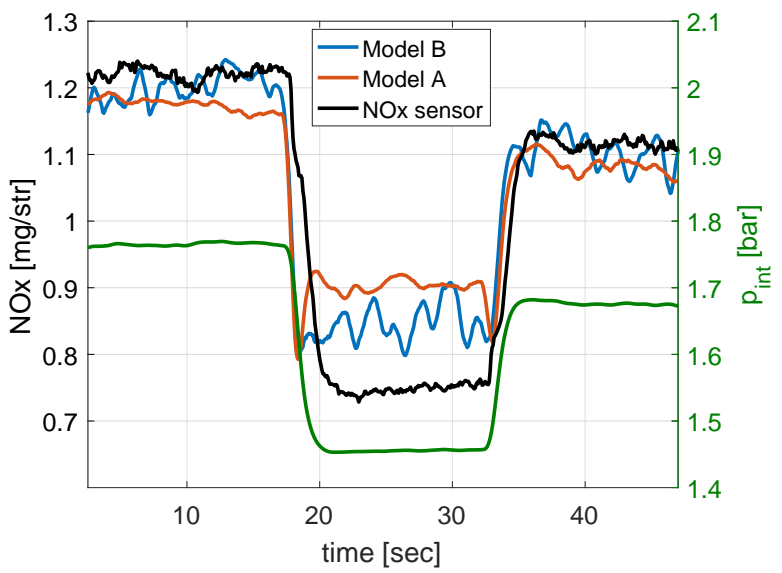

Figure 16: Model A, model B and NOx sensor output when varying TGV at $1600 \mathrm{rpm}, 15$ bar BMEP
An intake pressure increment increases the incylinder pressure curve and the adiabatic flame temperature, which becomes in a thermal NOx increment. Figure 16 illustrates that effect when varying intake pressure from 1.77 bar to 1.46 bar and reducing NOx from $1.2 \mathrm{mg} / \mathrm{str}$ to $0.75 \mathrm{mg} / \mathrm{str}$. Although, both models obtain similar results, model A shows an erratic transient of $1 \mathrm{sec}$ at intake pressure variations. This transient can be caused by crossed interference between the intake manifold dynamics of the air mass flow and the intake temperature evolution used for the volumetric efficiency calibration .

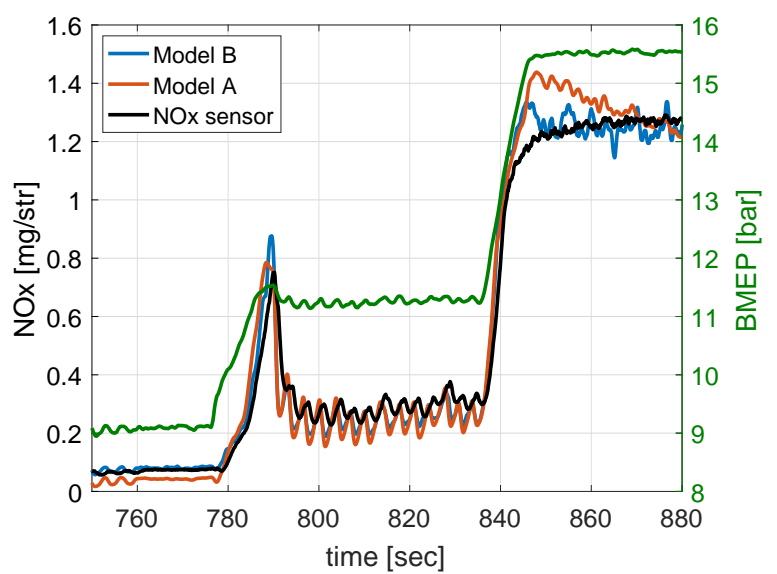

Figure 17: Model A, model B and NOx sensor output when performing a load step at $1600 \mathrm{rpm}$

When all settings are changed at the same time by performing a load step, the same aforementioned effects can be identified. Figure 17 compares model A and $\mathrm{B}$ during two load steps, from 9 to 15.5 bar. At 9 bar, where measured NOx are low, the $\mathrm{N}_{2} \mathrm{O}$ and prompt correction improves model $\mathrm{B}$ response. At the first step, the transient and the NOx oscillations are better predicted by the model. The sensor filters the signal because of the delay and its time response. Finally, when load is increased to 15.5 bar and EGR valve is closed, model A shows the same transient than at the EGR step, while model B follows the sensor measurement.

\section{CONCLUSIONS AND FUTURE WORK}

An analysis of NOx formation modelling was presented in order to improve current models. Finally, some improvements are proposed with a new model estimation procedure. It is based on dividing the frequency spectrum of the in-cylinder pressure signal in two regions: a first one with combustion information 
and a second one with the acoustical waves response. By using resonance to estimate the trapped mass, the method gives a NOx estimation by relaying only in the in-cylinder pressure sensor, a hot film anemometer at intake and a lambda sensor at exhaust. Finally, a correction for prompt and $\mathrm{N}_{2} \mathrm{O}$ mechanisms is also proposed for low adiabatic flame temperatures.

An Smart NOx Sensor, calibrated by an exhaust gas analyser Horiba system in steady operation, was used to illustrate the method capabilities in transient operation. The final model is capable of predicting NOx by a MAE smaller than $0.05 \mathrm{mg} / \mathrm{str}$ and showing a MRE bellow $10 \%$. Harnessing in-cylinder pressure resonant modes for an additional trapped mass measurement permits reducing the error a 25\% (from 0.055 to $0.044 \mathrm{mg} / \mathrm{str}$ ) and improves transient response by avoiding effects of temperature and mass flows transients. Furthermore, it offers a calibration procedure for MAF sensor when EGR valve is closed, avoiding NOx model bias when engine ages.

Errors on the final estimation can be related to calibration but also to trapped mass estimation. Future works on the topic should be focused on the dynamic system response, by including intake manifold dynamics, sensor time response and an observer of trapped mass and NOx for combining all measurements.

\section{REFERENCES}

[1] L. Rubino, P. Bonnel, R. Hummel, A. Krasenbrink, U. Manfredi, and G. De Santi. On-road emissions and fuel economy of light duty vehicles using PEMS: Chase-testing experiment. SAE International Journal of Fuels and Lubricants, 1(1):14541468, 2009.

[2] T. G. Vlachos, P. Bonnel, A. Perujo, M. Weiss, P. Villafuerte, and F. Riccobono. In-use emissions testing with portable emissions measurement systems (PEMS) in the current and future european vehicle emissions legislation: Overview, underlying principles and expected benefits. SAE International Journal of Commercial Vehicles, 7(1):199-215, 2014.

[3] M. Lindgren and P. . Hansson. Effects of transient conditions on exhaust emissions from two non-road diesel engines. Biosystems Engineering, 87(1):57-66, 2004.

[4] T. Johnson. Vehicular emissions in review. $S A E$ Int. J. Engines, 7:1207-1227, 042014.
[5] F. Baghery. Combustion noise level assessment in direct injection diesel engines by means of incylinder pressure components. Journal of Advances in Vehicle Engineering, 2(1):57-64, 2016.

[6] X. Lu, D. Han, and Z. Huang. Fuel design and management for the control of advanced compression-ignition combustion modes. Progress in Energy and Combustion Science, 37(6):741-783, 2011.

[7] F. Tschanz, A. Amstutz, C. H. Onder, and L. Guzzella. Feedback control of particulate matter and nitrogen oxide emissions in diesel engines. Control Engineering Practice, 21(12):18091820, 2013.

[8] N. Ladommatos, S. Abdelhalim, and H. Zhao. Control of oxides of nitrogen from diesel engines using diluents while minimising the impact on particulate pollutants. Applied Thermal Engineering, 18(11):963-980, 1998.

[9] J. Riegel, H. Neumann, and H. Wiedenmann. Exhaust gas sensors for automotive emission control. Solid State Ionics, 152-153:783-800, 2002.

[10] M. Mrosek, H. Sequenz, and R. Isermann. Identification of emission measurement dynamics for diesel engines. In IFAC Proceedings Volumes, volume 18, pages 11839-11844, 2011.

[11] T. Manchur and M. Checkel. Time resolution effects on accuracy of real-time NOx emissions measurements. SAE Technical Paper 2005-01-0674, 2005.

[12] C. Guardiola, H. Climent, B. Pla, and D. BlancoRodriguez. Ecu-oriented models for nox prediction. part 2: Adaptive estimation by using an nox sensor. Proceedings of the Institution of Mechanical Engineers, Part D: Journal of Automobile Engineering, 229(10):1345-1360, 2015.

[13] C. Guardiola, B. Pla, D. Blanco-Rodriguez, and P. O. Calendini. Ecu-oriented models for nox prediction. part 1: A mean value engine model for nox prediction. Proceedings of the Institution of $\mathrm{Me}$ chanical Engineers, Part D: Journal of Automobile Engineering, 229(8):992-1015, 2015.

[14] D. Kiha and M. Uchanski. Engine-out NOx models for on ECU implementation: A brief overview. SAE Technical Paper 2015-01-1638, 2015.

[15] C. Quérel, O. Grondin, and C. Letellier. State of the art and analysis of control oriented NOx models. SAE Technical Paper 2012-01-0723, 2012. 
[16] D. Cipolat. Analysis of energy release and NOx emissions of a CI engine fuelled on diesel and DME. Applied Thermal Engineering, 27(1112):2095-2103, 2007.

[17] C. T. Bowman. Kinetics of pollutant formation and destruction in combustion. Progress in Energy and Combustion Science, 1(1):33-45, 1975.

[18] J. Asprion, O. Chinellato, and L. Guzzella. Optimisation-oriented modelling of the NOx emissions of a diesel engine. Energy Conversion and Management, 75:61-73, 2013.

[19] S. D'Ambrosio, R. Finesso, L. Fu, A. Mittica, and E. Spessa. A control-oriented real-time semiempirical model for the prediction of NOx emissions in diesel engines. Applied Energy, 130:265279, 2014.

[20] C. Guardiola, J. J. López, J. Martín, and D. GarcíaSarmiento. Semiempirical in-cylinder pressure based model for NOx prediction oriented to control applications. Applied Thermal Engineering, 31(16):3275-3286, 2011.

[21] J. Asprion, O. Chinellato, and L. Guzzella. A fast and accurate physics-based model for the NOx emissions of diesel engines. Applied Energy, 103:221-233, 2013.

[22] C. Quérel, O. Grondin, and C. Letellier. Semiphysical mean-value NOx model for diesel engine control. Control Engineering Practice, 40:2744, 2015.

[23] J. D. Powell. Engine control using cylinder pressure: Past, present, and future. Journal of Dynamic Systems, Measurement and Control, Transactions of the ASME, 115(2 B):343-350, 1993.

[24] J. M. Luján, V. Bermúdez, C. Guardiola, and A. Abbad. A methodology for combustion detection in diesel engines through in-cylinder pressure derivative signal. Mechanical Systems and Signal Processing, 24(7):2261-2275, 2010.

[25] M. Baratta and D. Misul. Development and assessment of a new methodology for end of combustion detection and its application to cycle resolved heat release analysis in ic engines. Applied Energy, 98:174-189, 2012.

[26] J. Chung, S. Oh, K. Min, and M. Sunwoo. Realtime combustion parameter estimation algorithm for light-duty diesel engines using in-cylinder pressure measurement. Applied Thermal Engineering, 60(1-2):33-43, 2013.
[27] A. J. Torregrosa, A. Broatch, J. Martín, and L. Monelletta. Combustion noise level assessment in direct injection diesel engines by means of incylinder pressure components. Measurement Science and Technology, 18(7):2131-2142, 2007.

[28] J. M. Desantes, J. Galindo, C. Guardiola, and V. Dolz. Air mass flow estimation in turbocharged diesel engines from in-cylinder pressure measurement. Experimental Thermal and Fluid Science, 34(1):37-47, 2010.

[29] A. J. Torregrosa, P. Olmeda, J. Martín, and C. Romero. A tool for predicting the thermal performance of a diesel engine. Heat Transfer Engineering, 32(10):891-904, 2011.

[30] J. M. Desantes, A. J. Torregrosa, A. Broatch, and P. Olmeda. Experiments on the influence of intake conditions on local instantaneous heat flux in reciprocating internal combustion engines. Energy, 36(1):60-69, 2011.

[31] C. A. Finol and K. Robinson. Thermal modelling of modern engines: A review of empirical correlations to estimate the in-cylinder heat transfer coefficient. Proceedings of the Institution of Mechanical Engineers, Part D: Journal of Automobile Engineering, 220(12):1765-1781, 2006.

[32] F. Payri, J. Arrégle, J. Javier López, and E. Mocholí. Diesel NOx modeling with a reduction mechanism for the initial NOx coming from EGR or re-entrained burned gases. SAE Technical Paper 2008-01-1188, 2008.

[33] J. Arrégle, J. López, C. Guardiola, and C. Monin. Sensitivity study of a NOx estimation model for on-board applications. SAE Technical Paper 200801-0640, 2008.

[34] J.M. Desantes, J. Javier López, P. Redón, and J. Arrégle. Evaluation of the thermal $\mathrm{NO}$ formation mechanism under low-temperature diesel combustion conditions. International Journal of Engine Research, 13(6):531-539, 2012.

[35] U. Asad and M. Zheng. Exhaust gas recirculation for advanced diesel combustion cycles. Applied Energy, 123:242-252, 2014.

[36] J.B. Heywood. Internal Combustion Engine Fundamentals. McGraw-Hill, Inc., 1988.

[37] J. LeGare and T. Tamai. High temperature measurements for on-board diagnostics of LEV/ULEV systems. SAE Technical Paper 942054, 1994. 
[38] J. M. Luján, J. Galindo, J. R. Serrano, and B. Pla. A methodology to identify the intake charge cylinder-to-cylinder distribution in turbocharged direct injection diesel engines. Measurement Science and Technology, 19(6), 2008.

[39] P. Azzoni, G. Minelli, D. Moro, and G. Serra. A model for EGR mass flow rate estimation. $S A E$ Technical Paper 970030, 1997.

[40] F. Payri, J. Galindo, J. Martín, and Arnau F.J. A simple model for predicting the trapped mass in a DI diesel engine. SAE Technical Paper 2007-010494, 2007.

[41] J. Worm. An evaluation of several methods for calculating transient trapped air mass with emphasis on the delta $\mathrm{p}$ approach. SAE Technical Paper 2005-01-0990, 2005.

[42] Off J Eur Un 2009; L140. EU. regulation (EC) no $443 / 2009$ of the european parliament and of the council of 23 april 2009 setting emission performance standards for new passenger cars as part of the communityâĂŹs integrated approach to reduce $\mathrm{CO} 2$ emissions from light-duty vehicles.

[43] F. Payri, A. Broatch, B. Tormos, and V. Marant. New methodology for in-cylinder pressure analysis in direct injection diesel engines - application to combustion noise. Measurement Science and Technology, 16(2):540-547, 2005.

[44] X. Zhen, Y. Wang, S. Xu, Y. Zhu, C. Tao, T. Xu, and M. Song. The engine knock analysis - an overview. Applied Energy, 92:628-636, 2012.

[45] C.S. Draper. The physical effects of detonation in a closed cylindrical chamber. Technical report, National Advisory Committee for Aeronautics, 1938.

[46] Robert Hickling, Douglas A. Feldmaier, Francis H. K. Chen, and Josette S. Morel. Cavity resonances in engine combustion chambers and some applications. Journal of the Acoustical Society of America, 73(4):1170-1178, 1983.

[47] C. Guardiola, B. Pla, D. Blanco-Rodriguez, and P. Bares. Cycle by cycle trapped mass estimation for diagnosis and control. SAE Int. J. Engines, 7(3), 2014.

[48] J. M. Luján, C. Guardiola, B. Pla, and P. Bares. Estimation of trapped mass by in-cylinder pressure resonance in HCCI engines. Mechanical Systems and Signal Processing, 2015. Article in Press.

[49] A. Broatch, C. Guardiola, B. Pla, and P. Bares. A direct transform for determining the trapped mass on an internal combustion engine based on the in-cylinder pressure resonance phenomenon. Mechanical Systems and Signal Processing, 62:480489, 2015.

[50] Y.B. Zeldovich. The oxidation of nitrogen on combustion and explosions, 1946.

[51] M. Lapuerta, O. Armas, and J. J. Hernández. Diagnosis of DI diesel combustion from in-cylinder pressure signal by estimation of mean thermodynamic properties of the gas. Applied Thermal Engineering, 19(5):513-529, 1999.

[52] G. Woschni. A universally applicable equation for the instantaneous heat transfer coefficient in the internal combustion engine. SAE Technical Paper 670931, 1967.

[53] P. Tunestål. Self-tuning gross heat release computation for internal combustion engines. Control Engineering Practice, 17(4):518-524, 2009.

[54] U. Asad and M. Zheng. Fast heat release characterization of a diesel engine. International Journal of Thermal Sciences, 47(12):1688-1700, 2008.

[55] J. J. Hernández, J. Pérez-Collado, and J. SanzArgent. Role of the chemical kinetics on modeling NOx emissions in diesel engines. Energy and Fuels, 22(1):262-272, 2008.

[56] C. P. Fenimore. Formation of nitric oxide in premixed hydrocarbon flames. Symposium (International) on Combustion, 13(1):373-380, 1971.

[57] A. Broatch, C. Guardiola, P. Bares, and F.D. Denia. Determination of the resonance response in an engine cylinder with a bowl-in-piston geometry by the finite element method for inferring the trapped mass. International Journal of Engine Research, 2015.

[58] J. Galindo, J. R. Serrano, C. Guardiola, D. BlancoRodriguez, and I. G. Cuadrado. An on-engine method for dynamic characterisation of nox concentration sensors. Experimental Thermal and Fluid Science, 35(3):470-476, 2011. 